INTERNATIONAL DESIGN CONFERENCE - DESIGN 2018

https://doi.org/10.21278/idc.2018.0493

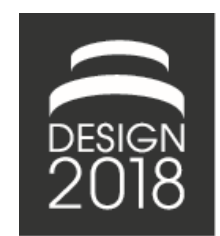

\title{
MEASURING DESIGN THINKING MINDSET
}

\author{
C. Dosi, F. Rosati and M. Vignoli
}

\begin{abstract}
This article describes the development and validation of a questionnaire designed to measure the Design Thinking Mindset self-awareness. A comprehensive review of the relevant literature revealed 19 constructs. An exploratory factor analysis of the responses of two samples $(\mathrm{N}=307)$ of Design Thinking professionals with some level of experience resulted in a 71-item instrument to assess DT Thinking Mindset based on 22 constructs. A measure of DT Mindset is relevant for research and practice, i.e. measuring the impact of different variables and designing more balanced and complete design teams.
\end{abstract}

Keywords: design thinking, mindset, research methodologies and methods, design learning

\section{Introduction and theoretical framework}

Many people consider themselves experts in Design Thinking (DT); many others feel that they have always been and they just did not know the name. Such broad familiarity with Design Thinking is interesting, as it goes deep in most people's identity. This happens because one of the most crucial elements in the Design Thinking approach is the Design Thinking mindset (e.g. Hassi and Laakso, 2011; Carlgren, 2013). DT professionals consider measuring the impact of DT an imperative to understand the development of the most essential characteristic of a Design Thinker, which is if he "thinks" in the proper way.

The Stanford University d.school Design Thinking manifesto calls the mindset a set of "vital attitudes for the Design Thinker to hold" (Both and Baggereor, 2010, p. II).

Academic literature is still scant and in disagreement on what the core elements of the Design Thinking mindset are and no evidence is present on their measurement. Fraser (2011) describes the designer's mindset to be composed of "Openness", "Empathy", "Intrinsic motivation", "Mindfulness", "Adjustment" and "Optimism". For Hassi and Laakso (2011) the mindset "describes the orientation towards the work at hand and the mentality on which problems are approached" and it is described by elements like "being experimental and explorative", "Being ambiguity tolerant", "being Optimistic" and "being future-oriented". Schweitzer et al. (2016) have identified 11 "Design Thinking Mindsets": "Empathetic towards people's needs and context", "Collaboratively geared and embracing diversity", "Inquisitive and open to new perspectives and learning", "Mindful of process and thinking modes", "Experiential intelligence", "Taking action deliberately and overt", "Consciously creative", "Accepting of uncertainty and open to risk", "Modelling behaviour", "Desire and determination to make a difference", "Critically questioning". Other authors have written about the characteristics of the mindset (Both and Baggereor, 2010; Carlgren, 2016a) and it is possible to identify some common constructs like being focused on the user, being empathetic, collaborative and open to diversity, being comfortable with ambiguity, embracing risk and experimentation, mindfulness and optimism. The application of these constructs could be different among authors, for example some authors interpret mindfulness as self- 
mindfulness (Fraser, 2011) or others confound the awareness of the process with the ability to combine the divergent and convergent thinking (Both and Baggereor, 2010; Brenner and Uebernickel, 2016; Schweitzer et al., 2016). Moreover, some authors have included in the description of the mindset some tools like prototyping, visualization, iteration and testing.

The ample literature review of the DT mindset performed during this research, shows that, to our knowledge, there are no measurement tools for the Design Thinking mindset. Schmiedgen et al. (2016) declares: "there can be none capable of adequately determining the specific impact or contribution of design thinking in an organizational setting due to the complexity of the situation" (p. 166).

This is not happening by chance, as many authors report the challenges to measure the DT mindset:

1. There are different ways to implement DT and it changes from one organization to another and also from the context (Marelaro et al., 2015)

2. "many very different practices are labelled design thinking-making them challenging to analyse" (Schmiedgen et al., 2016, p.168) so there is the risk to measure something that is not Design Thinking

3. Who is trying to measure the DT declares that their tools are not valid or are not real tools and they use tools that seem "a bit manufactured [fabricated]" (Schmiedgen et al., 2016, p.168). So far, the most valid measurement tools are feedbacks and customers satisfaction.

In this research, we refer to "mindset" as the set of attitudes, opinions, beliefs and behaviors that characterize an individual, a group, or an organization, mostly developed by experience.

The aim of this research is to develop and validate a questionnaire to assess Design Thinking Mindset metacognitive self-awareness on professionals. This instrument could be useful for both research and practice. For instance, academics could assess the development of Design Thinking Mindset in a Design Education pedagogical intervention, or in research projects measuring the impact of different variables. Individuals could assess their developments toward a mature Design Thinking Mindset after a Design project or organizations could use the instrument to design teams that are more balanced or complete in terms of Mindset.

\section{Design Thinking Mindset}

\subsection{Identification of the DT Mindset elements}

In order to build a measurement tool, we first started by identifying the elements that compose the DT mindset. To do that, we drew upon all scientific literature relevant to our study on google scholar and conducted a structured research. The selection of publications for this study was made on certain predetermined criteria. The first one being choosing only the papers published in scientific journals and eliminating all results related to books, conference articles, $\mathrm{PhD}$ thesis, working papers or paper with ssnr that result unpublished or program-related - for example programs related to some Schools (e.g. Aalto Design School, Stanford Design School) or other institutions (e.g. Design for all Institute of India). This does not mean that practical experiences are undermined; in fact, most of the literature on the DT mindset is born from a qualitative-exploratory approach in the practitioner's world. Another criterion led to excluding sectorial contributions like articles in clinical or mathematical journals.

Furthermore, we were careful in differentiating among papers that explained "design thinking" as a thinking process of design science where the focus is on the cognitive understanding versus the ones explicitly mentioning "design thinking" as a method for innovation, as applied in Fraser (2011) and Liedtka (2000). In the case of ambiguity, we have only listed the papers that explicitly mention design thinking as a method. We analysed the results with the aforementioned criterion from five variations of searches on google scholar employing combinations of keywords "design thinking" together with "mindset" or "mind" in the title or body of the scientific articles. The first iteration has looked for "Design Thinking Mindset" in the title; the second iteration looked for contributions presenting "Design Thinking Mindset" somewhere in the article. The third iteration looked for "Design Thinking Mind" in the title (no results) and the forth for "Design Thinking Mind" in the contribution. The fifth iteration looked for "Design Thinking" and "Mindset" somewhere in the article. We found 120 
individual contributions and after the application of the criteria mentioned before, we considered 17 papers.

The intent was to obtain a comprehensive collection of DT mindset elements by scrutinizing these 17 papers by noting how many times each element was mentioned. To achieve this, we considered the interpretation of the scientific article and we reported the element in the most objective way, mentioning the exact words of authors (e.g. "Judgmental" and "Social" in Carlgren, 2016a). In this phase, we listed 40 elements (some of them overlapping because of similar labelling). Then we reduced the 40 elements to 34 when the element was found less than two times in all the papers since we did not consider them as a real expression of the DT mindset. After a discussion in the research group, we decided to eliminate all the techniques and tools (e.g. prototyping) as they can be cited to support and enable different elements of the mindset; as Howard et al. (2015) state: "Collaboration, visualization and prototyping are used discretely to support elements of the process, rather than as core components" (p. 190). We carefully reconsidered all the 17 articles to focus our attention on the meaning that the authors were referring when quoting a specific element as part of the Design Thinking Mindset. We ended up with a more precise categorization where the resulting constructs are interpreted in a wider way. We identified 19 constructs: A) Tolerance for - Resilience of - Being comfortable with Ambiguity - Uncertainty / Embrace Uncertainty; B) Embracing Risk; C) Human centeredness; D) Empathy / Empathic; E) Mindfulness and awareness of process; F) Holistic view/consider the problem as a whole; G) Problem reframing; H) Team working; I) Multi-/inter-/cross- disciplinary collaboration; J) Open to different perspectives /diversity; K) Learning oriented; L) Experimentation or learn from mistake / from failure; M) Experiential intelligence / Bias toward action; N) Critical Questioning ("beginner's mind", curiosity); O) Abductive thinking; P) Envisioning new things; Q) Creative confidence; R) Desire to make a difference/have an impact/impactful /can change things/reverse norms/reach result/solve problem; S) Optimism to have an impact.

All of these items derive from an accurate analysis of the different elements found in the selected literature, where there authors independently clustered the 34 elements and then agreed on a final list of constructs. As an example, both Carlgren et al. (2016b) and Schweitzer et al. (2016) describe items related to concept of embracing risk and of ambiguity tolerance: Carlgren et al. refer to the initial problem re-formulation and Schweitzer et al. refer in particular to the process, namely to the risk of failure, to be open to accept the ambiguity in the outcome. Both of them include the aspect of using a holistic approach, which we considered as a separated item. In every paper authors are mentioning the central role of the users but some of them express this focus in term of empathy and deep user understanding (e.g. Carlgren et al., 2016b) while someone else only in one of the two terms (e.g. Schweitzer et al., 2016). We differentiate this concept into two items (Human centeredness and Empathy). The concept of collaboration is present in three constructs of our model, expressed in three different aspects (teamwork, multidisciplinary teams and open to diversity) but, for example, Schweitzer et al. (2016) include all these aspects under a single element (Collaborative geared and embracing diversity). In general, the final set of constructs is in line with the literature, excepted the tools the we have discarded because our model's aim is to describe attitudes of people implementing Design Thinking more than understand which are the needed elements to describe DT.

See Table 1 for a detail of this analysis in which in the columns there are the constructs and in line there are the 17 papers and there is an X every time the item is cited in a paper. 
Table 1. Design Thinking mindset in literature

\begin{tabular}{|c|c|c|c|c|c|c|c|c|c|c|c|c|c|c|c|c|c|c|}
\hline is & $m$ & $x$ & & & & & $x$ & & & & & & & & & $x$ & & \\
\hline$\mu$ & in & $x$ & & & & $x$ & & & & & & $x$ & $x$ & & & $x$ & & \\
\hline$\alpha$ & $n$ & $x$ & & & $x$ & $x$ & $x$ & $x$ & & & & & & $x$ & & $x$ & & \\
\hline$a_{1}$ & $n$ & $x$ & & & & & & & & $x$ & $x$ & & $x$ & $x$ & $x:$ & $x$ & & \\
\hline 0 & $a$ & $x$ & & $x$ & & & & $x$ & $x$ & $x$ & & & $x$ & $x$ & $x:$ & $x$ & & \\
\hline 乙 & 0 & $x$ & & & $x$ & $x$ & $x$ & & & & & & & & $x$ & $x$ & & \\
\hline 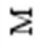 & $\infty$ & $x$ & $x$ & & $x$ & & $x$ & & & & & $x$ & & & $x ;$ & $x D$ & $x$ & \\
\hline$\mapsto$ & 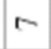 & $x$ & & & $x$ & & & & $x$ & $x$ & $x$ & $x$ & & & & $x$ & & \\
\hline$\Delta$ & $\infty$ & $x$ & & & & & & & & $x$ & $x$ & $x$ & & $x$ & $x ;$ & $x D$ & $x$ & \\
\hline$\curvearrowleft$ & $m$ & $x$ & & $x$ & & $x$ & & & $x$ & & & & & & $x ;$ & $x$ & & $x$ \\
\hline$\mapsto$ & 2 & $x$ & $x$ & & $x$ & & & & $x$ & $x$ & & & $x$ & & & $x$ & & \\
\hline 江 & 0 & $x$ & & $x$ & & $x$ & & & $x$ & & & & $x$ & & & $x$ & & \\
\hline ט & in & $x$ & & & & $x$ & & $x$ & & $x$ & & & & & & & $x$ & \\
\hline 山 & 1 & $x$ & & & & $x$ & & $x$ & & $x$ & $x$ & & $x$ & & & $x$ & & \\
\hline 비 & m & & & & & & & $x$ & & & & & & & & $x>$ & $x$ & \\
\hline 口 & $a$ & $x$ & & & & & $x$ & & $x$ & $x$ & & $x$ & $x$ & $x$ & & $x$ & & $x$ \\
\hline ن & 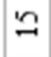 & $x$ & & $x$ & & $x$ & $x$ & $x$ & $x$ & $x$ & $x$ & $x$ & $x$ & $x$ & $x ;$ & $x>$ & $x ;$ & $x$ \\
\hline$m$ & 0 & $x$ & & $x$ & $x$ & & & & & $x$ & & & $x$ & & & $x$ & & \\
\hline 4 & $\infty$ & $x$ & & $x$ & $x$ & $x$ & & & & $x$ & & $x$ & & $x$ & & $x$ & & \\
\hline 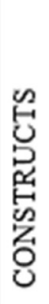 & 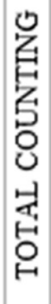 & 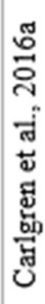 & 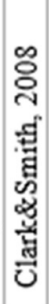 & 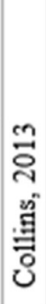 & 음 & 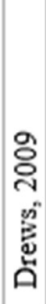 & 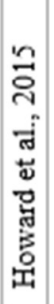 & 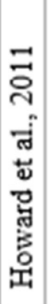 & 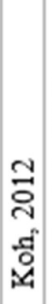 & 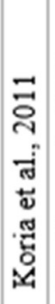 & 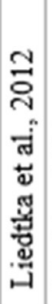 & 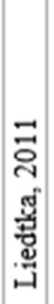 & 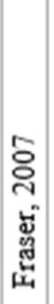 & 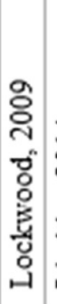 & 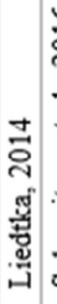 & 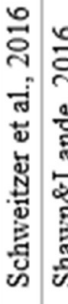 & 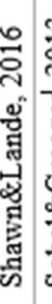 & 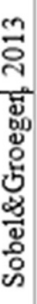 \\
\hline
\end{tabular}

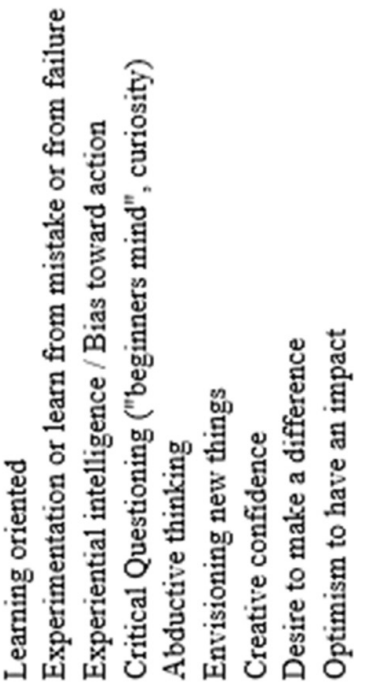

வ்

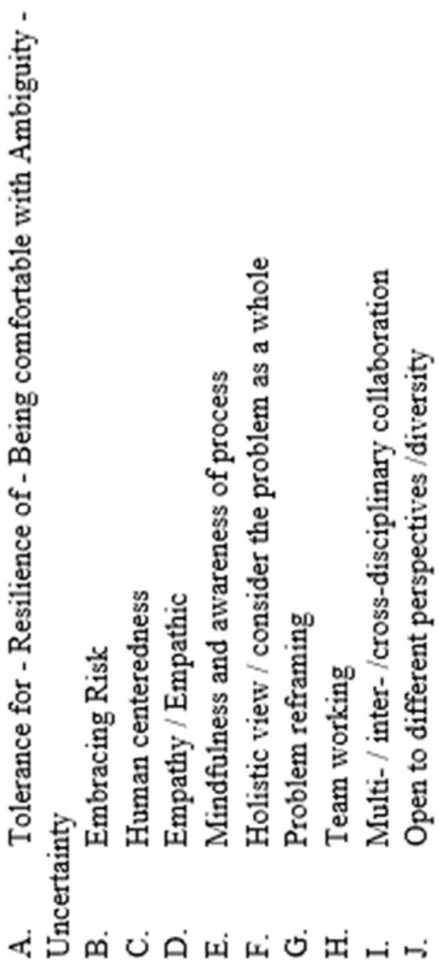




\subsection{Definition of DT mindset constructs}

For each construct, we report a brief definition emerging from literature.

A. Tolerance for - Resilience of - Being comfortable with Ambiguity - Uncertainty. Being comfortable with ambiguity means being used to leave doors open as long as possible, to consider a solution as an imprecise concept and "often inconclusive" (Collins, 2013, p.37), to take part in a process in which the outcome, the "volume of iterations" (Schweitzer et al., 2016, p. 11) and the time needed to reach the outcome are unknown (Schweitzer et al., 2016).

B. Embracing Risk. Embracing risk includes "risking failure and failing fast" (Carlgren et al., 2016b, p.51) and the inclination to take risks in term of process (energy, time, ...) that allow a deep exploration of the context and of new solutions, however crazy/foolish/mad and unconventional. In fact, designers are aware of exploration (Carlgren et al., 2016b) and expansion of the design knowledge are not able to leave risk taking out of consideration/ cannot ignore the risk taking. It is a necessary condition for the design (Fraser, 2007), for the innovation and for receiving a subsequent reward (Davis, 2010).

C. Human centeredness. Human centeredness means focusing "on understanding human behaviors, needs, and values" (Howard and Davis, 2011, p. 18), a way to solve "complex and strategic problems" (Howard et al., 2015, p. 184). "Being user-centric does not mean asking customers what they want; rather, it is about finding out what they need" (Koh, 2012, p. 31). If you want to be truly human centered, "customer co-creation is not an option" (Liedtka, 2011, p. 17), it should be a key requirement (Liedtka, 2011).

D. Empathy / Empathic. "Empathy is the foundation of a human-centered design process." (Both and Baggereor, 2010, p. 1). It is the ability to see things "from multiple perspectives" (Carlgren et al., 2016a, p. 51), to create "customer intimacy" (Liedtka, 2011, p. 16) is "the ability to see and experience through another person's eyes, to recognize why people do what they do" (Schweitzer et al., 2016, p. 6). Being empathetic includes "being open, avoiding being judgmental and being comfortable with people with different backgrounds and opinions" (Carlgren et al., 2016, p. 46).

E. Mindfulness and awareness of process. Design Thinkers are aware of the process in the sense that they know where they are in the design process, whether they are involved in a converging or diverging phase, if they have to be "highly generative versus when it is necessary to converge on a single solution path" (Schweitzer et al., 2016, p. 8).

F. Holistic view/consider the problem as a whole. This is the ability to consider the whole problem, taking into account many factors like "socioeconomic patterns, relationships, dependencies" (Koria et al., 2011, p. 6), "including customer needs, technical feasibility, organizational constraints, regulatory implications, competitive forces, resource availability, Strategic Implications as well as the Costs and Benefits of Different Solutions Proposals" (Schweitzer et al., 2016, p. 12), thus achieving a 360 degree view of the problem.

G. Problem reframing. Problem reframing means reformulating "the initial problem" (Carlgren et al., 2016a, p. 47) in a "meaningful and holistic way" (Drews, 2009, p. 41), "widen, challenge the problem" (Carlgren et al., 2016a, p. 47), taking all the findings and discovering a right interpretation.

H. Team working. Design Thinkers needs to collaborate, share their knowledge, discuss using visualization tools in order to better communicate and clarify what they $<$ have in mind. It is considered a pre-condition of the implementation of Design Thinking: "Affinity for Teamwork: [...] designers routinely work closely with other designers and experts from other fields." (Owen, 2006, p. 5). Team working "is about sharing and jointly developing knowledge, and supporting other team members" (Efeoglu et al., 2013, p. 251) and for some authors is fundamental as designing "is not something done exclusively inside one's head, but is often accomplished in interaction with other people, using expressions such as collaborative integrative thinking " (Hassi and Laakso, 2011, p. 56). Meinel and Leifer (2012a) give an advice: "never go hunting alone. Go hunting in teams, choosing one that is small and agile with a maximum of diversity." (p. 3).

I. Multi- / inter- / cross- disciplinary collaboration. Collaboration "is essential to design thinking" (Davis, 2010, p. 6536) and each Design Thinker needs to collaborate in a multidisciplinary team with other people with different backgrounds, perceptions and perspectives, or collaborating with people from other organizations. Stanford d.School calls it "radical collaboration": bring together innovators 
with varied backgrounds and viewpoints. Enable breakthrough insights and solutions to emerge from the diversity (Both and Baggereor, 2010).

J. Open to different perspectives/diversity. Diversity can be understood as "encompassing collaboration in diverse teams, and the integration of diverse outside perspectives throughout the process" (Carlgren et al., 2016a, p. 48), not always the term refers to skills but also to hierarchy (Carlgren et al., 2016a). Diversity of "perspectives, talents and experiences" (Liedtka, 2014, p. 44) and "expertise" (Koh, 2012, p. 31) that "encourage collaboration beyond the usual disciplines to tap into knowledge and experiences" (Schweitzer et al., 2016, p. 7). "[It is] a philosophy of looking across the border so to look into other industries, how do they solve things that are similar" (Carlgren et al., 2016a, p. 48) and then expand your own horizons to other organizations, but also to universities or design companies.

K. Learning oriented. Learning orientation is a key feature of Design Thinkers. Design thinkers have "an appetite for learning" (Schweitzer et al., 2016, p. 8), "a desire to learn, including learning about others, challenging existing frameworks and seeking new contexts in which to learn something" (Schweitzer et al., 2016, p. 8). Their main source of learning is action: "learning by doing" through observations, rapid prototyping, and hypothesis formulation.

L. Experimentation or learn from mistake or from failure. Design Thinkers are confident in experimenting with failures because, due to their ambiguity, the failure is seen as a way to discover new opportunities, a way to learn. Failing is not seen as a waste of time, but it is even encouraged (Davis, 2010): "fail often and fail soon" (Carlgren et al., 2016a, p. 48). Experimentation, according to Carlgren, is "a bias towards testing and trying things out in an iterative way, and moving between divergent and convergent ways of thinking."(Carlgren et al., 2016a, p. 47).

M. Experiential intelligence / Bias toward action. Design Thinker are characterized by the Experiential Intelligence: the ability to make tangible what's not, "to bring them to life" (Liedtka, 2011, p. 17), "to understand and activate all five human senses to make innovation tangible, known, and vibrant" (Clark and Smith, 2008, p. 9), to transform "the concepts generated in the What if stage into feasible, testable models" (Liedtka, 2011, p. 17), to prefer "action-oriented behavior over discussion and conceptual or analytical behavior" (Schweitzer et al., 2016, p.10).

N. Critical Questioning ("beginners mind", curiosity). It is "the exercise of questioning everything" (Davis, 2010, p. 6536), is the ability of "asking the right question" (Drews, 2009, p. 41), "to keep an open-mind about possibilities" (Schweitzer et al., 2016, p. 13), to have a "beginner mind", that is going to the origin of the problem by avoiding losing "sight of what [the team] is working towards" (Schweitzer et al., 2016, p. 13)

O. Abductive thinking. It is "the logic of what might be" (Lockwood, 2009, p. 31), it means "moving from what is "known" to the exploration of alternative solutions" (Fraser, 2007, p. 72), is "the generation of new ideas" (Carlgren et al., 2016a, p. 40). It is the ability of "being future oriented" (Carlgren, 2016a, p. 51), of "building conclusions from incomplete information, making small leaps into a partially known future" (Collins, 2013, p. 37).

P. Envisioning new things. It is the ability to make ideas tangible, "to envision possibilities" (Liedtka and Ogivile, 2012, p. 9; Liedtka, 2014, p. 41) thanks to the use of drawings, mock-ups and "bring them to life" (Liedtka and Ogivile, 2012, p. 9; Liedtka, 2014, p. 41). It "includes the ability to 'see' the end result as a concrete and complete picture: to 'see' the complete solution played out in its most robust form, to 'see' the way the business will work with all of the necessary partners and enterprise systems' and even to 'see' success in the market and the potential paradigm shift that a breakthrough can trigger" (Fraser, 2011, p. 75).

Q. Creative confidence. Creativity is "a mental activity, but it can also be part of a systems model" (Lockwood, 2009, p. 37), is the "ability to think differently" (Davis, 2010, p. 6533), to challenge "traditional processes and styles" (Lockwood, 2009, p. 37). "Creativity is critical to DT as a mode to explore and express less tangible and more subjective content by making the abstract or non-experienced come to life" (Schweitzer et al., 2016). The creative confidence is manifested when "person's trust in tackling problems of which you rather know what you don't know than what you actually know" (Jobst et al., 2012, p. 36) and it "refers to one's own trust in his creative problem-solving abilities" (Meinel and Leifer, 2012b, p. 5) 
R. Desire to make a difference. DT professionals have the desire and therefore are determined to have an impact, to make a difference, for example by creating something visual that breaks through, or are inclined to turn a discussion into a strategic intent. They have "a desire to develop the skills, structures and processes to generate value from valuable insights." (Schweitzer et al., 2016, p. 13) and they are determined to persuade someone of their idea and justify it if they think it is valuable.

S. Optimism to have an impact. Optimism, called urgent optimism by Kelley and Kelley (2013), is "a state of mind of DT teams [...] [is the] ability to move forward, knowing they will not always be right but optimistic about their ability to experiment and conduct midcourse correction further down the road" (Schweitzer et al., 2016, p. 12).

\section{Method}

\subsection{Instrument development}

Following standard criteria for the development of valid and reliable questionnaires (Kazi and Khalid, 2012), we began by examining the relevant literature on Design Thinking Mindset. This literature, reviewed earlier in this article, provided theoretical validation for item construction in a questionnaire targeted to self-assess Design Thinking Mindset Constructs. For each of the identified constructs, we looked for validated scales that could be an inspiration for us. We started the review with a particular focus on the innovation literature and to psychometric literature. We developed a questionnaire composed by 130 questions, divided in 19 sections (one for each construct). Answers follow a 5-point Likert scale from "strongly agree" to "strongly disagree". We opted for such a scale because the ultimate purpose of the instrument was to track development of metacognitive awareness for purposes of either self-assessment or research.

This initial list of items was subjected to six experts' judgment for redundancy, content validity, clarity, and readability to check the content coherence among questions and the constructs we were testing. Later, we checked the content validity. We asked to each expert if each question is coherent with the related construct. He had to judge this coherence on a 4-point Likert scale $(1=$ not relevant, $2=$ somewhat relevant, $3=$ relevant, $4=$ very relevant). We calculated the Content Validity Index for every Item (CVI-I) and we decided to maintain only questions that have an index greater than $80 \%$.

With this content validity, we obtain a survey composed of 84 questions.

\subsection{Instrument validation}

We tested this final version of the questionnaire with two different sample. Sample 1 is composed by 74 people, who have already done at least two Design Thinking projects in collaboration with different companies. Sample 2 is composed by 233 University students who have attended a specific course (implementing a Design Thinking project). We can state that each person of the two samples have some experience in the Design Thinking approach. The survey was online (through SurveyMonkey) and we estimated the compilation time to be 17 minutes. The answer rate was equal to $82 \%$ for first sample and $14 \%$ for the second one.

With all these data, we implemented an exploratory factor analysis to verify if the theoretical structure of the survey corresponds to the one based on experience. The analysis was repeated for each one of the 19 sections of the survey.

Since the analysis is explorative, we used the "Principal axis factorization" as an extraction method and we implemented some preliminary tests like the KMO Kaiser-Mayer-Okin's test (to determine if the sample size is big enough to extract factors in a reliable way) and the Bartlett's Test (to determine the homogeneity of data). The KMO values needs to be higher than 0,5 .

Furthermore, we decided to do a factor rotation. First, we implemented "direct oblimin" factor rotation, an oblique rotation that implies that factors are correlated, as we assumed at the beginning. In case two emerging factors resulted very low correlated (observing the correlation index between factors), we performed a "Varimax" rotation. For each question, if the factor loading was less than 0,5 , we decided to eliminate that question. In case a question presented a difference of factor loading less than 0,3 between two factors, that question was eliminated. 


\section{Results}

\subsection{Exploratory factors analysis}

The investigation of the Design Thinking Mindset Constructs was conducted through SPSS (SPSS, Inc., 2005) to determine whether there was empirical support for separate factors pertaining to metacognitive awareness of the constructs, and to identify any items that might be removed from the questionnaire. We examined each construct for the presence of more than one factor and of any unsatisfactory items in order to identify the appropriate factors and items.

Table 2 presents the results of the entire factor analysis.

Table 2. Results of the factor analysis

\begin{tabular}{|c|c|c|c|c|c|c|}
\hline Constructs & $\begin{array}{c}\text { Extract } \\
\text { factors }\end{array}$ & KMO & Significance & $\begin{array}{c}\text { \% of } \\
\text { variance }\end{array}$ & $\begin{array}{c}\text { \% } \\
\text { cumulated }\end{array}$ & $\begin{array}{c}\text { Correlation between } \\
\text { factors }\end{array}$ \\
\hline A & 1 & 0,64 & $<0,001$ & 65,4 & 65,4 & - \\
\hline B & 1 & 0,50 & $<0,001$ & 73,8 & 73,8 & - \\
\hline C & 1 & 0,63 & $<0,001$ & 62,1 & 62,1 & - \\
\hline D & 1 & 0,71 & $<0,001$ & 52,3 & 52,3 & - \\
\hline E & 1 & 0,64 & $<0,001$ & 57,3 & 57,3 & - \\
\hline F & 1 & 0,66 & $<0,001$ & 64,4 & 64,4 & - \\
\hline G & 1 & 0,65 & $<0,001$ & 57,0 & 57,0 & - \\
\hline H & 2 & 0,58 & $<0,001$ & $53,8+26,7$ & 80,5 & - \\
\hline I & 1 & 0,74 & $<0,001$ & 57,3 & 57,3 & - \\
\hline J & 1 & 0,76 & $<0,001$ & 57,7 & 57,7 & 0,51 \\
\hline K & 1 & 0,81 & $<0,001$ & 54,0 & 54,0 & 0,54 \\
\hline L & 2 & 0,78 & $<0,001$ & $50,5+19,3$ & 69,8 & - \\
\hline M & 2 & 0,57 & $<0,001$ & $51,7+28,1$ & 79,8 & - \\
\hline N & 1 & 0,63 & $<0,001$ & 65,4 & 65,4 & - \\
\hline O & 1 & 0,63 & $<0,001$ & 83,1 & 83,1 & - \\
\hline P & 1 & 0,65 & $<0,001$ & 59,5 & 59,5 & - \\
\hline Q & 1 & 0,84 & $<0,001$ & 82,6 & 82,6 & - \\
\hline R & 1 & 0,66 & $<0,001$ & 68,5 & 68,5 & \\
\hline S & 1 & 0,70 & $<0,001$ & 76,1 & 76,1 & \\
\hline
\end{tabular}

As we can see from the table, it has always been possible to do the analysis, because the KMO is always at least 0,5 , the Significance of the Bartlett's Test is always optimal and the covered variance is always at least $50 \%$. From 84 questions and 19 factors, we obtained a questionnaire of 71 questions and 22 factors.

For three constructs (H,L,M) we extracted two factors: H) Team Working was split into Ha) Team Knowledge and $\mathrm{Hb}$ ) Team Members' Interaction; L) Experimentation or learn from mistake / from failure was split in La) Experimentation and Lb) Learning from Mistake; M) Experiential intelligence / Bias toward action was split in Ma) Bias for action and Mb) Transforming in something tangible what's not, resulting in a total of 22 constructs.

Table 3 presents the final questionnaire. 
Table 3. The validated questionnaire measuring the Design Thinking mindset

\begin{tabular}{|c|c|}
\hline \multicolumn{2}{|c|}{ A. Tolerance for - Being comfortable with Ambiguity - Uncertainty } \\
\hline D1 & I feel comfortable with what is unknown. \\
\hline D2 & I prefer new contexts rather than familiar ones. \\
\hline D4 & I am comfortable in dealing with unsolved problems. \\
\hline D6 & I enjoy the fact that a solution can result from unexpected directions. \\
\hline D7 & $\begin{array}{l}\text { I am comfortable in dealing with problems with which I cannot predict if they will be successfully } \\
\text { solved }\end{array}$ \\
\hline \multicolumn{2}{|c|}{ B. Embracing Risk } \\
\hline D10 & I am comfortable in taking risks \\
\hline D11 & I like taking many chances, also if it leads me to make mistakes \\
\hline \multicolumn{2}{|c|}{ C. Human centeredness } \\
\hline D13 & I actively involve users in diverse phases of the design process \\
\hline D14 & People are source of inspiration while identifying the direction of the design solution \\
\hline D15 & During the design activity I dedicate a considerable amount of time to understand what users need \\
\hline \multicolumn{2}{|c|}{ D. Empathy / Empathic } \\
\hline D17 & I can tune into how users feel rapidly and intuitively \\
\hline D18 & I am comfortable to see problems from the users point of view \\
\hline D19 & I am comfortable to put myself into the shoes of user \\
\hline D20 & I easily empathize with the concerns of other people \\
\hline \multicolumn{2}{|c|}{ E. Mindfulness and awareness of process } \\
\hline D21 & I am capable to recognize when there is the necessity to iterate one phase of the process \\
\hline D22 & I trust in the process to find new discoveries, rather than focusing on where the outcomes may fall \\
\hline D23 & I am able to recognize when we are in a divergent or convergent phase of the process \\
\hline \multicolumn{2}{|c|}{ F. Holistic view / consider the problem as a whole } \\
\hline D24 & I am able to consider what I am doing from a broader perspective \\
\hline D25 & $\begin{array}{l}\text { I am able to understand which are the impacts on the external environment of the solution we are } \\
\text { proposing }\end{array}$ \\
\hline D26 & I am comfortable to insert into the final solution factors coming from a broader vision \\
\hline \multicolumn{2}{|r|}{ G. Problem reframing } \\
\hline D27 & I think it is important to reframe the initial problem in order to achieve a good result \\
\hline D28 & I am interested in better understanding the problem that is given to us \\
\hline D29 & I am capable to reframe the initial problem statement \\
\hline \multicolumn{2}{|c|}{ H. Team Working } \\
\hline \multicolumn{2}{|c|}{ Ha. Team knowledge } \\
\hline D31 & I am comfortable to accept the group's decision even if I have a different opinion \\
\hline D32 & I prefer to work in a team rather than working alone \\
\hline \multicolumn{2}{|c|}{ Hb. Team members' interactions } \\
\hline D33 & I am comfortable to share my knowledge with my team mates \\
\hline D34 & I am comfortable to develop new knowledge with other team mates \\
\hline \multicolumn{2}{|c|}{ I. Multi-/ inter-/ cross-disciplinary collaborative teams } \\
\hline D35 & I am comfortable working with people from outside of my organization \\
\hline D36 & I think in team is preferable having different competences \\
\hline D37 & I am comfortable to work with people having diverse perspectives and abilities from mine \\
\hline D38 & I like to spend time with people doing different work than mine \\
\hline \multicolumn{2}{|c|}{ J. Open to different perspectives /diversity } \\
\hline D39 & I am comfortable to change my opinion \\
\hline D40 & I am open to collaborate with people having different backgrounds \\
\hline D43 & I find value in other people's diversity (perspectives, abilities) \\
\hline D44 & I believe that teams with diverse perspectives result in superior outcomes \\
\hline
\end{tabular}




\begin{tabular}{|c|c|}
\hline \multicolumn{2}{|c|}{ K. Learning oriented } \\
\hline D47 & I am comfortable to see a problem like an opportunity to learn \\
\hline D48 & I am comfortable to implement what I learn \\
\hline D49 & I am comfortable to learn from experiences \\
\hline D50 & I am comfortable to learn from observations \\
\hline D51 & I am comfortable to receive feedbacks and learn from them \\
\hline D52 & I look for something that I don't know \\
\hline \multicolumn{2}{|c|}{ L. Experimentation or learn from mistake or from failure } \\
\hline \multicolumn{2}{|c|}{ La. Experimentation } \\
\hline D53 & I continually try new things \\
\hline D54 & I am comfortable to try new approaches to solve problems \\
\hline D55 & I am comfortable to experiment \\
\hline \multicolumn{2}{|c|}{ Lb. Learn from mistake } \\
\hline & I recognize the importance of failing in order to learn \\
\hline D57 & I am comfortable to make prototypes in order to explore \\
\hline D58 & I am capable to discuss mistakes and learn from them \\
\hline \multicolumn{2}{|c|}{ M. Experiential intelligence / Bias toward action } \\
\hline \multicolumn{2}{|c|}{ Ma. Bias for action } \\
\hline D59 & It is easier to gain knowledge through hands \\
\hline & I prefer doing rather than thinking \\
\hline \multicolumn{2}{|r|}{ Mb. Transforming in something tangible what's not } \\
\hline D61 & I am comfortable transforming ideas into something tangible \\
\hline D62 & I am comfortable transforming hypothesis in something to be tested \\
\hline \multicolumn{2}{|r|}{ N. Critical Questioning ("beginners mind", curiosity) } \\
\hline D63 & I look for something new in a new situation \\
\hline D64 & I am curious about what I don't know \\
\hline D65 & I generally seek as much information as I can in new situations \\
\hline \multicolumn{2}{|c|}{ O. Abductive Thinking } \\
\hline D66 & I am comfortable to invent or simulate alternative contexts of use of the solution \\
\hline D67 & I am comfortable to invent new conditions for future possibility of the project \\
\hline D68 & I am comfortable to build conclusions from incomplete information \\
\hline D69 & I am comfortable to take decisions from a plausible hypothesis \\
\hline \multicolumn{2}{|c|}{ P. Envisioning new things } \\
\hline D71 & I am capable of keeping multiple options open at the same time \\
\hline D72 & I can foresee different outcomes of a project \\
\hline D73 & I am comfortable to use prototypes to represent new ideas \\
\hline \multicolumn{2}{|c|}{ Q. Creative confidence } \\
\hline D74 & I think I can use my creativity to efficiently solve even complicated problems \\
\hline D75 & I am comfortable to think something new, different from what already exists \\
\hline D76 & I am sure I can deal with problems requiring creativity \\
\hline D77 & I believe in my abilities to creatively solve a problem \\
\hline \multicolumn{2}{|c|}{ R. Desire to make a difference } \\
\hline D78 & I have the desire to change the status quo \\
\hline D80 & I desire to create value with the final solution \\
\hline D81 & I desire to have an impact on people around me \\
\hline \multicolumn{2}{|c|}{ S. Optimism to have an impact } \\
\hline $\mathrm{D} 82$ & I think I can overcome difficulties \\
\hline D83 & I am comfortable to see a problem like an opportunity \\
\hline D84 & I am comfortable to positively think and act \\
\hline
\end{tabular}




\section{Discussion and conclusions}

This preliminary study describes the development and validation of a questionnaire to assess Design Thinking Mindset metacognitive self-awareness on professionals. This questionnaire could be used as a self-reported measure, being useful to assess the development of a professional competence.

We made an in-depth description of the Design Thinking mindset as a set of different attitudes and this is the first published attempt of measuring it.

We conducted an exploratory factor analysis with two samples of Design Thinking professionals with some level of experience, in order to assess the strength of the 19 constructs model derived from literature. After the validation, we can state that Design Thinking mindset is composed by 22 constructs and the questionnaire is composed of 71 items that use a 5-points Likert scale.

This study has some limitations, the first one being the respondent sample size. Greater dimensions would increase the analysis' efficiency and reliability. Moreover, we decided to test it with people having limited experience in Design Thinking and this aspect could have conditioned the results.

Future research should validate this questionnaire with a confirmatory factor analysis and could test it with people having a higher experience in Design Thinking, in order to compare if metacognitive awareness of DT Mindset attributes are different depending on the working experience. It could be interesting to submit the survey before and after a Design Thinking project to test if people's attitudes have changed.

For a practical standpoint, this result could be combined with traditional KPIs, used in organizations, in order to assess the impact of Design Thinking. The questionnaire could also be used as a tool to design innovation teams by knowing in advance team members' attitudes.

Concluding, we believe this research has an impactful potential both in literature and in the organizational world.

\section{References}

Brenner, W. and Uebernickel, F. (2016), Design thinking for innovation: Research and practice, Springer.

Both, T. and Baggereor, D. (2010), Bootcamp bootleg, Design School Stanford, Palo Alto.

Carlgren, L., Rauth, I. and Elmquist, M. (2016a), "Framing Design Thinking: The Concept in Idea and Enactment", Creativity and Innovation Management, Vol. 25 No. 1, pp. 38-57. https://doi.org/10.1111/caim.12153

Carlgren, L., Elmquist, M. and Rauth, I. (2016b), "The Challenges of Using Design Thinking in IndustryExperiences from Five Large Firms", Creativity and Innovation Management, Vol. 25 No. 3, pp. 344-362. https://doi.org/10.1111/caim.12176

Carlgren, L. (2013), Design thinking as an enabler of innovation: Exploring the concept and its relation to building innovation capabilities, $\mathrm{PhD}$ thesis, Chalmers University of Technology.

Clark, K. and Smith, R. (2008), "Unleashing the power of design thinking", Design Management Review, Vol. 19 No. 3, pp. 8-15. https://doi.org/10.1111/j.1948-7169.2008.tb00123.x

Collins, H. (2013), "Can design thinking still add value?", Design Management Review, Vol. 24 No. 2, pp. 35-39. https://doi.org/10.1111/drev.10239

Davis, B.M. (2010), "Creativity \& innovation in business 2010 teaching the application of design thinking to business", Procedia-Social and Behavioral Sciences, Vol. 2 No. 4, pp. 6532-6538. https://doi.org/10.1016/j.sbspro.2010.04.062

Drews, C. (2009), "Unleashing the full potential of design thinking as a business method", Design Management Review, Vol. 20 No. 3, pp. 38-44. https://doi.org/10.1111/j.1948-7169.2009.00020.x

Efeoglu, A., Møller, C., Sérié, M. and Boer, H. (2013), "Design thinking: characteristics and promises", 14th International CINet Conference on Business Development and Co-creation.

Fraser, H. (2011), "Business Design: Becoming a Bilateral Thinker”, Rotman Magazine, Vol. Winter, pp. 71-76.

Fraser, H. (2007), "The practice of breakthrough strategies by design", Journal of business strategy, Vol. 28 No. 4, pp. 66-74. https://doi.org/10.1108/02756660710760962

Hassi, L. and Laakso, M. (2011), "Design Thinking in the Management discourse; defining the elements of the concept", 18th International Product Development Management Conference, IPDMC.

Howard, Z. and Davis, K. (2011), "From solving puzzles to designing solutions: Integrating design thinking into evidence based practice", Evidence Based Library and Information Practice, Vol. 6 No. 4, pp. 15-21. https://doi.org/10.18438/B8TC81 
Howard, Z., Senova, M. and Melles, G. (2015), "Exploring the role of mindset in design thinking: Implications for capability development and practice", Journal of Design, Business \& Society, Vol. 1 No. 2, pp. 183-202. https://doi.org/10.1386/dbs.1.2.183_1

Jobst, B., Köppen, E., Lindberg, T., Moritz, J., Rhinow, H. and Meinel, C. (2012), “The Faith-Factor in Design Thinking: Creative Confidence Through Education at the Design Thinking Schools Potsdam and Stanford?", In: Plattner, H., Meinel, C. and Leifer, L. (Eds.), Design Thinking Research, Springer, Berlin, Heidelberg, pp. 35-46. https://doi.org/10.1007/978-3-642-31991-4_3

Kazi, A.M. and Khalid, W. (2012), "Questionnaire designing and validation", Journal of the Pakistan Medical Association, Vol. 62 No. 5, p. 514.

Kelley, T. and Kelley, D. (2013), Creative Confidence: Unleashing the creative potential within us all, Crown Business, NY.

Koh, S. (2012), "Design Thinking: A Culture of Innovation”, Social Space, pp. 30-33. http://ink.library.smu.edu.sg/lien_research/95/

Koria, M., Graff, D. and Karjalainen, T.M. (2011), "Learning design thinking: International design business management at Aalto university", REDIGE Review on Design, Innovation and Strategic Management, Vol. 2 No. 1 .

Liedtka, J. and Ogilvie, T. (2012), "Helping business managers discover their appetite for design thinking”, Design Management Review, Vol. 23 No. 1, pp. 6-13. https://doi.org/10.1111/j.1948-7169.2012.00165.x

Liedtka, J. (2000), "In defense of strategy as design", California Management Review, Vol. 42 No. 3, pp. 8-30. https://doi.org/10.2307/41166040

Liedtka, J. (2014), "Innovative ways companies are using design thinking”, Strategy \& Leadership, Vol. 42 No. 2, pp. 40-45. https://doi.org/10.1108/SL-01-2014-0004

Liedtka, J. (2011), "Learning to use design thinking tools for successful innovation”, Strategy \& Leadership, Vol. 39 No. 5, pp. 13-19. https://doi.org/10.1108/10878571111161480

Lockwood, T. (2009), "Transition: How to become a more design-minded organization”, Design Management Review, Vol. 20 No. 3, pp. 28-37. https://doi.org/10.1111/j.1948-7169.2009.00019.x

Marelaro, N., Ganguly, S., Steinert, M. and Jung, M. (2015), "The personal trait myth: a comparative analysis of the innovation impact of design thinking tools and personal traits", In: Plattner, H., Meinel, C. and Leifer, L. (Eds.), Design thinking research, Springer, Heidelberg, pp. 41-57.

Owen, C.L. (2006), Design thinking: Driving innovation. [online] The Business Process Management Institute. Available at: http://www.bpminstitute.org/resources/articles/design-thinking-driving-innovation

Meinel, C. and Leifer, L. (2012a), "Design Thinking Research", In: Plattner, H., Meinel, C. and Leifer, L. (Eds.), Design thinking research, Springer Science \& Business Media, pp. 1-10. https://doi.org/10.1007/978-3-64231991-4_1

Meinel, C. and Leifer, L. (2012b), “Design Thinking Research”, In: Plattner, H., Meinel, C., Leifer, L. (Eds.), Design thinking research, Springer Science \& Business Media, pp. 1-11. https://doi.org/10.1007/978-3-64221643-5_1

Schmiedgen, J., Spille, L., Köppen, E., Rhinow, H. and Meinel, C. (2016), "Measuring the Impact of Design Thinking”, In: Plattner, H., Meinel, C. and Leifer, L. (Eds.), Design Thinking Research, Springer International Publishing, pp. 157-170. https://doi.org/10.1007/978-3-319-19641-1_11

Schweitzer, J., Groeger, L. and Sobel, L. (2016), “The design thinking mindset: An assessment of what we know and what we see in practice", Journal of Design, Business \& Society, Vol. 2 No. 1, pp. 71-94. https://doi.org/10.1386/dbs.2.1.71_1

Dr.-Ing. Matteo Vignoli, Assistant Professor

University of Modena and Reggio Emilia, Department of Sciences and Methods for Engineering

Via Amendola 2, 42122 Reggio Emilia, Italy

Email: matteo.vignoli@unimore.it 